\title{
10 health stories that mattered this week: Apr. 6-10
}

- The average health care cost in the last year of life is nearly $\$ 54000$, according to an Ontario study in PLOS One. The total annual cost for last-year care in Ontario is $\$ 4.7$ billion, accounting for about $10 \%$ of all government-funded health care.

- Wind turbine noise may be annoying but there's no evidence of a threat to public health, reported the Council of Canadian Academies. An expert-panel review of 32 potential adverse health effects concluded that there was no evidence that the noise causes hearing loss, limited evidence that it disturbs sleep and inadequate evidence of any other health effect considered.

- The Canadian military struggles to attract psychiatrists, psychologists and social workers in some parts of the country because it cannot offer competitive salaries. In 2002, the military set a goal of having 454 mental-health workers to treat soldiers with problems such as post-traumatic stress disorder but never met that quota.

- Forty-two percent of severely obese patients who undergo surgery will suffer complications, $31 \%$ will need repeat surgery and $17 \%$ will die in hospital, according to an Alberta study of 111 patients with a body mass index of 35 or higher. The researchers suggest that some of the problems with recovery may be due to diets high in calories but low in vitamins and minerals.

- Shoppers Drug Mart recalled one lot of expired Alesse 21 birth control pills sold in British Columbia, Alberta, Saskatchewan and Manitoba. The pills expired in September 2014 and may be less effective. Health Canada said it is monitoring the recall and advised consumers to check the expiry dates on all medications.

- An antibiotic-resistant strain of the bacteria Shigella is a growing threat, according to public health experts. Resistance to ciprofloxacin, the main drug used to treat Shigella infections, has steadily increased over the past five years.

- British Columbia hosted a summit on workplace violence in health care in response to a series of unrelated attacks on a doctor, nurses and others last year. Facility redesigns, including the use of tempered glass partitions between health workers and aggressive patients, were among solutions proposed at the summit.

- A chain of clinics in British Columbia and Alberta are misleading dementia patients with unproven claims that they can cure the disease through "brainwave optimization," a CBC investigation revealed. Valentus clinics purport to treat dementia, concussion, depression and a host of other health problems by recording the electrical activity in a person's brain and playing it back to them as music.

- Canadian medical schools may soon have to figure out how to introduce physician-assisted dying into their curricula. It may be complicated to implement and out of step with traditional medical principles, but preparing doctors to assist patients in this decision will be necessary if the practice becomes legal, say medical educators.

- Ontario Health Minister Eric Hoskins said the province is working on a policy to curb exorbitant hospital parking fees. According to Hoskins, the Liberal government plans to cap or cut fees for frequent hospital visitors, in keeping with pledges made during the provincial election last June. Hospital visitors pay up to $\$ 25$ a day for parking, and rates have risen in recent years. Lauren Vogel, Roger Collier, CMAJ

CMAJ 2015. DOI:10.1503/cmaj.109-5039 